\title{
CLAUDIO GUILLÉN Y LA TEORÍA DE LA NOVELA
}

\author{
Enric SULLÀ \\ Universitat Autònoma de Barcelona
}

Enric.Sulla@uab.es

$\mathrm{N}$

o quisiera que se me leyera a mí, sino a Claudio Guillén. Pero en esta ocasión me interpondré entre el lector o lectora y la obra del maestro, aunque desearía que sólo fuera para que acto seguido la curiosidad o el interés llevaran a leer los textos originales. De lo que sigue, por lo tanto, reivindico el acierto, si lo he tenido, de hilvanar un discurso sobre la teoría de la novela, que incorpora algunas generalizaciones sobre la novela como género y la novela española en particular, desde el Lazarillo pasando por Galdós hasta algunos novelistas contemporáneos, que ha adquirido una disposición que quizá Claudio Guillén no reconocería como suya y una inmovilidad que su ausencia hace irreparable. Ofrezco en suma una suerte de antología de textos de Guillén cuya intención es convencer a quien lea estas líneas de la importancia histórica e interés crítico de la labor del maestro. Si hay quien está ya convencido de ello, le invito a repasar los matices de un pensamiento teórico, crítico e histórico de gran altura.

Impresiona que desde el artículo sobre «La disposición temporal del Lazarillo», de 1957 (1988: 49-65), hasta las páginas dedicadas a novelas y novelistas en su último libro, De leyendas y lecciones, de 2007, transcurran casi cincuenta años ${ }^{1}$. Se trata de un largo trayecto del que destacaré algunos autores de referencia y sobre todo los problemas teóricos que interesaron a Claudio Guillén casi siempre y para los que fue hallando conceptos sucesivamente puestos al día. Como cierre de este preámbulo me permitiré afirmar que cuando Guillén publica Entre lo uno y lo diverso, en 1985, su información sobre teoría de la novela era tan sólida como actual, francamente innovadora dentro del panorama de la teoría literaria española de entonces.

En ese primer artículo Guillén se ocupa ya de uno de los aspectos de la narrativa al que más atención dispensó: las «formas temporales», utilizando una «orientación teórica», la teoría de la novela «tal como entonces se desenvolvía» (1988: 11), para pasar después a la teoría de los géneros literarios (1988: 12). En este movimiento combinaba Guillén tres formas de investigación que, con Wellek,

\footnotetext{
${ }^{1}$ Alguno más si se tiene en cuenta un artículo de 1955 que Guillén incluye en la bibliografía Entre lo uno y lo diverso (1985a: 457). La bibliografía más completa disponible de Guillén se halla en Sin fronteras. Ensayos de Literatura Comparada en homenaje a Claudio Guillén (Villanueva et alii, 1999: 283-287).
} 
consideraba indivisibles: la crítica, la historia y la teoría de la literatura, tomando «en consideración la tensión creadora que existe a lo largo de los siglos, y es acaso historiable, entre poética y poesía. O entre diversos modelos culturales y el acto de escribir» (1988: 12). Pero lo que interesa aquí es que, en aquel primer artículo, se valía del bergsoniano Thibaudet para afirmar que «en la temporalidad está la clave de la composición novelesca», puesto que la novela arranca «del libre e imprevisible transcurso del tiempo» (1957: 52), punto de partida para señalar la «necesidad de desarrollar un concepto temporal de la composición o disposición novelesca» (1957: 53). Que se apoye en el autor francés no es óbice para que Guillén dedique una densa nota a pie de página a comentar el «ritmo» de la novela, concepto que extrae del novelista E. M. Forster (1927), y la «forma espacial» que detectó Joseph Frank en la narración moderna (1957: 53 n. 11).

Lo cierto es que, al estudiar el Lazarillo, Guillén se detiene primero en la unidad de la obra, luego en su adscripción a un género para pasar luego a la disposición temporal, puesto que la «forma de la novela es la proyección [...] de la persona en el tiempo». Sostiene Guillén que toda novela tiene tres planos temporales: uno primero de «narración, o sea, el momento en que el narrador cuenta, habla o escribe» y dos «niveles integrados en la trama de la acción misma»: uno sería el cronológico o público (el tiempo del calendario) y otro personal y psicológico, «el de los hechos de la conciencia» (1957: $58)^{2}$. Tardará Guillén unos años y algunas lecturas en hallar una etiqueta para los cambios de ritmo, aceleraciones y desaceleraciones, que detectaba en el Lazarillo (lo destacaré más adelante), novela en la que aprecia una tensión temporal, pues considera que el «tiempo está ahí, sí, pero para ser vencido, así como la realidad social o moral está ahí para ser subyugada por la voluntad del héroe» (1957: 64)3․

Es fácil comprobar que Guillén dedicó numerosas páginas a considerar el género como categoría, muchas de ellas centradas en la novela picaresca, en las que se combinaba en concreto el intento de definir qué es el género «picaresca» (en una perspectiva europea, plenamente comparatista) estableciendo de paso sus características (1962: 71-10) con la preocupación por generalizar sobre el género «novela» o narrativo (1965-1968a: 107-134 y 1965-1968b) sin descuidar el análisis de textos en los que coexisten modelos distintos (como en el Guzmán de Alfarache) o que inauguran una vía (como El Abencerraje). Quizá esa línea de investigación le hizo ver la necesidad de unos conceptos generales que pudieran servir para poner orden en el estudio, histórico y sistemático, de los textos: los cauces de presentación o de comunicación ${ }^{4}$; los géneros propiamente dichos; unas modalidades literarias, «cualidades, vertientes principales, vetas que [...] recorren transversalmente» la obra literaria (la ironía, la sátira, lo grotesco, la alegoría, la parodia, lo fantástico, etc.); y, finalmente, las formas que son los «procedimientos tradicionales de interrelación, ordenación o limitación de la escritura» (1985a: 163-167). Más tarde, en otro contexto, prescinde de los cauces de presentación (por

\footnotetext{
${ }^{2}$ Para refrendar esa triple distinción Guillén cita a pie de página tanto La montaña mágica de Thomas Mann como la olvidada Physiologie du roman, de la no menos olvidada Nelly Cormeau (1947).

${ }^{3}$ En el curso de su examen del tiempo, Guillén cita a G. Poulet y J.-P. Sartre, además de aludir a W. Faulkner (1957: 6365 , n. 24 y 27$)$.

${ }^{4}$ Así traduce Guillén radicals of presentation, fórmula que toma prestada de Anatomy of criticism de N. Frye (1957: 246251). En un marco más actual, probablemente se podría hablar de modelos o tipos de texto, que serían, en una clasificación muy divulgada: la narración, la descripción, la argumentación, la explicación y el diálogo (Adam, 1992).
} 
demasiado generales quizá) e incluye, en cambio, los temas (2006: 24), acercándose un poco más al índice de su obra sistemática, Entre lo uno y lo diverso.

En el territorio que acotan estos conceptos, ¿qué aspectos de la novela le interesan a Claudio Guillén? Diría yo que se suele fijar en la coexistencia de cauces de presentación (como la narración y la descripción en La Regenta), en la movilidad de los géneros (como la novela más reciente o el complejo espacio del diálogo), en la combinatoria de modalidades (ironía y sátira en Galdós, por ejemplo) y formas (como la cronología narrativa, la alternancia de escenas y resúmenes o entre tipos de discurso, la interacción entre lo narrado y el narrador) y, finalmente, en los temas (como el individuo y el tiempo). Me temo que resulta una obviedad decir que tal interés responde a una aguda sensibilidad por lo plural, lo múltiple y lo complejo, tal como se pone de manifiesto en ficciones modernas (lo afirma él mismo al hilo de un comentario de La Regenta) donde «se entreveran, se concilian o entran en colisión la continuidad y la discontinuidad, la integridad y la fragmentación: mundos abiertos, dominios y zonas plurales que se superponen y entrecruzan, multiplicidad de lenguas y culturas, "pluralidad de sistemas en movimiento"» (1985a: 37).

Esa misma capacidad para deslindar niveles o planos en la investigación literaria y para proponer conceptos cuya aplicación al análisis de los textos resulte eficaz, propicia que Guillén acoja de manera favorable el estructuralismo, tal como se observa en la introducción a Literature as system, donde aborda el concepto de estructura en el marco de una "search for an "order" or a "sense" in a fasechanging, time-filled, historical world left to its own devices - bereft of any external or eternal source of meaning» (1971: 6). Con buen criterio, distingue Guillén dos sentidos del término estructura: uno, el más habitual, confunde el concepto con forma; otro, más científico, que localiza en Lévi-Strauss, en que las estructuras «se nos aparecen como transformaciones locales de un repertorio latente, transhistórico, de significaciones» (1974: 142-144 y 145, pero cito por 1985a: 375). No puede, por lo tanto, sorprender que decida adoptar este último concepto tomando la inequívoca perspectiva de un historiador de la literatura que se dobla de comparatista (1971: 7), con el objetivo de «estudiar la ordenación histórica de unos modelos - ante todo, de unos géneros literarios-que componen la poética de una época» (1974: 175).

Guillén no desdeñó, por lo tanto, la «modalidad estructuralista de pensamiento» aplicada a la investigación de las formas narrativas, puesto que «se abría al intento de localizar no unas meras estructuras [...] internas, reducidas al recinto de la narración o unas narraciones, sino un vocabulario de metaestructuras virtuales, accesibles a todo relato, sobrevoladoras de obras singulares y cambios históricos» (1985a: 204 y también 192; la cursiva pertenece al original). Los modelos son hoy bien conocidos: apoyándose en los trabajos pioneros de los formalistas rusos y de V. Propp (aunque también de E. Souriau), la primera oleada estructuralista la configuran A.-J. Greimas, C. Bremond y T. Todorov. Claro que si se consulta el célebre número 8 de la revista Communications (1966), se comprobará que esos nombres figuran en la portada al lado de R. Barthes, el auténtico referente del grupo, y G. Genette. No era, sin embargo, el proyecto de unos idéntico al de los otros, o no lo fue por lo menos a la larga, si bien es cierto que todos ellos colaboraron en la edificación de una «ciencia del 
relato en general» (1985a: 204 y 192), es decir, la narratología, tal como lo pone de manifiesto Todorov en su Grammaire du Décameron (1969), cuyo objeto es la narratividad, un «esquema único, abstracto, [que] ha de reflejar la unicidad [...] de la gramática y del lenguaje en general» (1985a: 204). O, como dice el mismo Guillén, la narratología, «[m]ás que de cierto género, como la novela, el cuento, la novella, o la novela corta, [...] trata de las condiciones constituyentes de toda narración». Le inquieta, sin embargo, que se piense que estamos ante «formas totalizadoras», porque «en la mayoría de los casos observamos una pluralidad de "elementos formales"» (1985a: 192).

Es lógico que Guillén se apresure a señalar una dificultad en esa etapa primera del análisis estructural del relato, que consiste en la «eliminación de aquellas propiedades del lenguaje que no se reducen a las relaciones sintácticas: léxico, figuras, estilo, etcétera» (1985a: 204), para reclamar que la narratividad no se considere con independencia de la escritura. Eso es lo que cree que logra Barthes en $S / Z$ (1970) cuando diluye el análisis estructural en un minucioso análisis textual abierto a una «pluralidad de significaciones», superando de esa manera la atención excluyente a la historia (Todorov) o a las acciones mismas (Bremond). Le interesa mucho más, por lo tanto, la segunda fase de la narratología, que parte de la relación indivisible entre los niveles del relato que los formalistas designaron como fábula y trama (1985a: 193) y Genette como histoire y récit, es decir, la «concatenación de acontecimientos» y el «enunciado narrativo mismo», compenetrados ambos con las palabras (1985a: 205). A esa fase adscribe Guillén las obras de Iuri M. Lotman, Cesare Segre, Gérard Genette, Franz K. Stanzel, Dorrit Cohn y Seymour Chatman, por este orden, pero a quienes concede un espacio significativo al hablar de narrativa es a Genette, Stanzel y Cohn, con alguna mención destacada a Segre, no sin advertir que de sus obras «proceden terminologías y distinciones aún no unificadas», razón por la que se limita a destacar «dos o tres rasgos generales que las caracterizan» (1985a: 205).

Es de destacar que uno de los aspectos de la obra literaria que más interesa a Guillén es

[...] la aparición progresiva de lo que no es sino uno de los elementos de una construcción verbal [...] que la crítica viene denotando mediante conceptos de estratificación [...]. Cuando pasamos de un género a otro, o de un cauce de comunicación a otro, es evidente que los estratos no son siempre los mismos; pero lo que sí persiste y se reitera es la estratificación como estructuras de estructuras, como principio básico de ordenación del fenómeno polimórfico que llamamos literatura (1985b: 37) ${ }^{6}$.

Más aún, la «estratificación, condición general del fenómeno literario, se vuelve en sus realizaciones concretas al propio tiempo sumamente compleja y especializada, como si de hecho se acentuasen las propiedades de un determinado cauce de presentación» (1985a: 193). De ahí que Guillén señale la vinculación de los estratos en narrativa «mediante el concepto de significación: la

\footnotetext{
${ }^{5}$ De hecho Guillén habla de fábula y «sujeto», quizá condicionado por la traducción francesa, sujet, del ruso sjuzet, que el libro de referencia de Erlich traduce como plot, que a su vez la versión española de la obra da como «argumento» (1969). La historia más reciente del formalismo transcribe el término como siuzhet aunque se entienda que designa la trama (Sanmartín 2008: 231-232). Véase la nota 8.

${ }^{6}$ Cuando se refiere a los estratos de la obra literaria, Guillén tiene bien presente a Roman Ingarden, por supuesto (1985b: 38-39 y 49 y 1985a: 192-193).
} 
intriga es el significado del discurso» ${ }^{7}$, lo que supone que «todo es narratividad en el proceso de significación de una narración analizada como tal» (1985a: 194). Advierte, con todo, que «el análisis crítico es por fuerza selectivo; y que si diversos cauces o distintas formas convergen en una obra, o en un género [...], el modelo de estratificación más idóneo dependerá de la prioridad que se previamente se conceda a determinado cauce o forma» (1985a: 194).

El «Discours du récit» de Gérard Genette le parece un estudio de «excepcional riqueza», un análisis «enormemente sugestivo»(1985a: 205-206). Observa de manera muy significativa que el método es «pluriestructural»o, mejor, «poliformal», superando la búsqueda de la narración primera, origen de todas las narraciones. Le interesa sobremanera que Genette perciba simultáneamente no dos sino tres estratos superpuestos que configuran una narración: récit, histoire y narration, traducidos respectivamente por relato, historia y narración o «acto de contar» (1985a: 206). Es sabido que Genette toma como objeto de estudio casi exclusivo la obra maestra de Proust, de innegable riqueza y complejidad formal, lo que le exigen un vaivén constante entre crítica e historia literaria ${ }^{8}$. Lo cierto es que los tres estratos se entrelazan de manera constante y de sus interrelaciones «brotan no incontables pero sí muy copiosas y variadas formas: el relato es polimórfico» (1985a: 206; la cursiva es del original). Pero Guillén acude al concepto más general de Genette, el de diégesis ${ }^{9}$, para decir que este es

[...] un mundo envolvente cuya existencia la lectura novelesca postula desde un principio, pero cuya naturaleza va siendo evocada muy poco a poco por el estrato verbalmente más completo y descriptivo, que es el récit o discurso narrativo. De éste se va desprendiendo un «discurso de las cosas», la manifestación progresiva de todo cuanto significan y sugieren los objetos, espacios, movimientos y otras interrelaciones que componen el mundo singular de la novela (1985b: 37-38).

El contacto de la historia con el relato y con la narración sugiere preguntas que no permiten olvidar la importancia de la temporalidad en la configuración de cualquier relato, dimensión que se asocia, por cierto, con el tiempo histórico en las novelas más recientes. Al respecto insiste Guillén: «Narrar es vivir y hacer vivir el tiempo - encauzándolo, conformándolo, invirtiéndolo, entregándolo al buen capricho del lector [...], subyugándolo, quizá salvándolo...» (1985a: 207). O dicho de otro modo: «Narrar es ante todo modelar el tiempo, medirlo, reinventarlo o distribuirlo» (2003-2006b: 498; también 1998b: 252). Parece imposible, pues, separar la temporalidad de la narratividad, aunque no se puede olvidar que no todo es narración en una novela, en la que muy a menudo suele haber pausas descriptivas que no se escapan, a pesar de todo, del fluir del tiempo: «Mirar, admirar, penetrar en lo visible es también vivir, es también una forma de actividad» (1985a: 207). Analizando la descripción contenida en el primer párrafo de La Regenta concluye Guillén que «[e]1 mundo representado [...] es indivisible de la temporalidad. No hay pausa ni quietud sino diégesis dinámica» (1985a: 208). Cosas, lugares y personas,

\footnotetext{
${ }^{7}$ Dentro el esquema terminológico propuesto por Segre, por intriga (intreccio) hay que entender trama (Segre 1974 y Sullà 2001: 169-173), tal como lo recoge Guillén (1985a: 194).

${ }^{8}$ Advierte Guillén que precisamente ese propósito «individualizador» provoca el reproche de Todorov (1974: 143).

${ }^{9}$ Guillén define el término con palabras del mismo Genette: «el universo espacio-temporal designado por el relato» (1985a: 207).
} 
[t]odo queda temporalizado por el arte del cuentista: por la interacción del relato, la historia y la narración. No es concebible un acontecimiento absolutamente aislado, del todo inocente ante el curso del tiempo. El suceso, desde el momento en que pertenece al cuento, ocurre «después de», o «antes de», o «repetidamente», o «usualmente», o «una sola vez», o «por última vez», etcétera (1985a: 208-209).

Sucede que «[1] a conciencia del tiempo fundamenta los cauces narrativos», es decir, formas o procedimientos (1985a: 209) ${ }^{10}$. Esa aparente certeza no es obstáculo para que en otro lugar se pregunte: «El tiempo de las cosas, el tiempo de los personajes y el tiempo de la historia, ¿cómo se compaginan?» (1985b: 42).

Ahora bien, las «dimensiones de lo que Genette llama diégesis admiten múltiples posibilidades y sus direcciones son reversibles. La historia acaba por tomar un solo rumbo, por asumir una sola forma unilineal. No así los rasgos y cualidades de lo representado, que son plurales y hasta contrapuestos» (1985b: 48). En otro pasaje matiza un poco más: «La morfología de un mundo de ficción es mucho más compleja que la historia, por fuerza limitada, que se deduce del relato que se desarrolla» (1985b: 62). No menos oportuna es la siguiente explicación que une varios de los términos que vengo comentando: «El novelista - a lo Balzac- aspira a construir mundos unificados (la "diégesis" de los narratólogos [...]), pero su intuición de la heterogeneidad de lo real hace que muchas veces la novela se subdivida [...] en una pluralidad de "dominios narrativos"» $(1985 \mathrm{a}: 36){ }^{11}$.

Del complejo análisis del tiempo narrativo de Genette, Guillén se fija en lo que llama el tempo del relato, «la velocidad del enunciado verbal en contraposición con el tiempo de la narración», es decir, la duración, y en sus cuatro formas: la elipsis, la pausa, la escena y el sumario. Le interesa, por cierto, un aspecto del orden temporal, una de las anacronías, la predicción (una variante de la anticipación o prolepsis), que ocurre cuando «se anuncia por anticipado un suceso ulterior» (1985a: 211), caso que ilustra con la Crónica de una muerte anunciada, de Gabriel García Márquez. En concreto se fija en los «vaticinios que se cumplen» y concluye que sólo el narrador «puede anunciar lo venidero», otra muestra de su incontestable autoridad en el mundo narrativo (1985a: 212) ${ }^{12}$.

La Theorie des Erzählens (1979), de Franz Stanzel, es otra de las obras que destaca Guillén. Stanzel parte del principio de que toda narración queda mediatizada, es decir, «distanciada, modelada, evaluada, percibida, sentida», por un narrador: «El modelo de comunicación que hoy tenemos presente encierra no al autor real, bien sea novelista [...], bien sea dramaturgo o poeta, sino a esa voz que impulsa y da vida al trato del lector con las palabras, configurándolas y de tal suerte mediatizando el objeto representado» (1985a: 213). En el libro citado se estudian los grados de mediatización en la novela que, como era de esperar, resultan ser relativos y variados. De las tres situaciones narrativas arquetípicas que propone Stanzel la que parece interesar más a Guillén es la «situación personal», caracterizada por «el intento de superar la mediatización por la ilusión de lo inmediato», puesto que

\footnotetext{
${ }^{10}$ Véase también 1985b: 40.

${ }^{11}$ Le interesa también a Guillén la clasificación de Genette de las diferentes clases de narración intercalada o «relato metadiegético», llamando la atención sobre la «imagen especular», la mise en abîme de Gide (1985a: 232).

${ }^{12}$ Guillén propone también como ejemplos determinadas intervenciones del ciego del Lazarillo y del abate Blanès de $L a$ chartreuse de Parme.
} 
quien mediatiza no es el narrador mismo, que se esconde, sino un personaje reflector, tal como propone H. James (1985a: 213; la cursiva es del original). Las otras dos situaciones son la pseudoautobiográfica, «cuyo narrador es un personaje incluido en el mundo presentado», y la «autorial», «cuyo narrador queda fuera del mundo» (1985a: 214).

Reconoce Guillén que el análisis de Stanzel es de una gran riqueza y destaca al menos tres méritos. En primer lugar, no le interesa a éste tanto dar una taxonomía de formas, una clasificación de objetos dados, cuanto las «variaciones y modulaciones de estas formas, en sus combinaciones y fusiones tal como aparecen en una novela» (Stanzel 1978: 247, en 1985a: 214). En segundo lugar Stanzel proporciona una «enriquecida visión histórica del desenvolvimiento de las formas narrativas», mérito que por cierto también le reconoce Guillén a Genette (1985a: 214). En último lugar, queda expedito el camino para al examen de lo que Stanzel llama la «dinamización» del género narrativo, o sea, «de cómo se intensifica la mediatización por medio de unos cambios de táctica formal a lo largo de una misma novela. Esta tercera perspectiva, consecuencia de las dos primeras, nos ayuda a percibir los cambios de ritmo y de enfoque [...] que enriquecen y vitalizan un relato» (1985a: 215). Señala Stanzel que tales procesos «se vuelven, asimismo, convencionales», lo que no es óbice para que a menudo «la parte final de una novela reanim[e] o sorprend[a] al lector mediante estos dinamismos formales», recurriendo, por ejemplo, a un «narrador periférico», cuyo papel sea necesario reconsiderar al final la novela (1985a: 215). Justamente ese proceso de dinamización es el que analizaba con acierto Guillén en su artículo inaugural sobre el Lazarillo sin hallar ni el marco teórico ni el término adecuado para describirlo.

El mismo título del libro de Dorrit Cohn, Transparent minds $(1978)^{13}$, destaca su objetivo: «presentar una tipología de las modalidades narrativas de conocimiento de la interioridad de los personajes». Un objetivo que encaja con el aserto de Guillén de que «la novela supone el conocimiento por el narrador de la vida interior de sus personajes» (2003-2006b: 469 y 486), aserto corroborado por «las mejores novelas del siglo XX y principios del XXI [en que] se admite como punto de partida la opacidad del hombre, es decir, de su vida íntima», por lo que se convierte en privilegio del narrador (y detrás suyo del novelista) hacer transparente esa intimidad (2003-2006b: 508). En su útil obra, Cohn esclarece tres formas fundamentales de psicología imaginada, recursos empleados por el narrador para revelar dicha intimidad: la «psiconarración», que es el «discurso del narrador desde fuera, que se avecina a la conciencia del personaje, a su interioridad»; el «monólogo citado», que es el «discurso mental del personaje desde dentro, en primera persona y en el momento mismo de la acción», que incluye el soliloquio y el llamado «monólogo interior»; y, por fin, el monólogo narrado», que es el «discurso mental del personaje reproducido por el narrador desde fuera y en tercera persona», y que como es sabido incluye el discurso indirecto libre (1985a: 217) ${ }^{14}$. Aunque advierte que estas formas

\footnotetext{
${ }^{13}$ Guillén también cita elogiosamente a Cohn en Múltiples moradas (1998a: 291).

${ }^{14}$ Es digno de mención que Guillén no entre a discutir el punto de vista, uno de los más importantes de la teoría narrativa, al que Genette por cierto dedica páginas brillantes, y que tan útil le resultaría en relación a la representación del discurso de los personajes, obra del narrador al fin y al cabo. Guillén se limita a tratarlo en un breve párrafo, como de pasada,
} 
se modifican si se trata de novelas pseudoautobiográficas o en «primera persona», lo que le interesa a Guillén es la presencia y rendimiento de la primera de estas formas en La Regenta (1985a: 218-219) ${ }^{15}$. Estudioso de la epístola (en lo que tiene de diálogo tácito e inconcluso) como género (1998: 177233), a Guillén no podía dejar de interesarle Mijail Bajtin, cuya concepción del lenguaje como diálogo da razón de la pluralidad social y linguiística, preocupación constante de aquél ${ }^{16}$. Para Bajtin, en efecto, el diálogo, en un sentido lato, define al hombre:

La heterogeneidad del hombre, fronterizo del otro, ocupado en el diálogo incesante con el otro, se confunde con el carácter plural del lenguaje, cuyas tendencias unitarias luchan sin éxito por suprimir la abundancia de lenguas que rodean toda situación expresiva y significativa: [es] lo que Bajtin denomina «heteroglosia» [...] El ser humano es, al igual que la novela, una «mezcla de estilos», como dice Todorov, y un proceso inconcluso, por cuanto el diálogo que lo fundamenta implica una multitud de palabras ajenas (1985a: 238$)^{17}$.

En concreto, la «heteroglosia» («multiplicidad constituyente de discursos y estilos» [1985a: 36]) le parecía la idea «más interesante» de Bajtin y, por supuesto, aplicable a la novela, porque «el novelista cruza muchas veces la frontera que divide la ficción de la historia vivida» (1985a: 17 y 174), observación que no deja de ser una interpretación que reduce mucho el alcance de la teoría bajtiniana. Concluye Guillén que «dos cosas son características de Bajtin: [1] la aplicación [...] de un principio dialógico a toda la historia de la literatura occidental, a la Lingüística y a la Antropología filosófica; y [2] la agilidad extrema con que pasa, tratando de diálogo o asimismo de novela, del uso literal de un término al uso figurado», motivo por el que Todorov puede hablar de intertextualidad, término que no acaba de convencer a Guillén (1985a: 237-238) ${ }^{18}$.

Sin olvidar la perspectiva teórica, sería del mayor interés examinar los artículos que Guillén dedicó a Galdós (2006), Clarín (1985b) y Pardo Bazán (1989b), que constituyen una parte sustancial de De leyendas y lecciones (2007: 13-87) ${ }^{19}$, pero no me lo permite el espacio disponible. Así que me fijaré en las páginas que Guillén dedicó a la novela española contemporánea limitándome, por la razón expuesta, a entresacar algunas ideas de un extenso trabajo, «Novelar de nuevo», recogido en ese misma colección ${ }^{20}$. Después de un breve prólogo, en el que Guillén ofrece un par de rasgos de una tendencia que él considera significativa de la novela contemporánea, procede al estudio de cuatro

mencionando a Percy Lubbock (sistematizador y divulgador de las ideas de H. James), dentro de su estudio de la perspectiva (1968: 352).

${ }^{15}$ En su estupendo estudio Guillén recupera páginas de un artículo publicado en 1985 (2007: 35-64).

${ }^{16}$ En el índice de Entre lo uno y lo diverso (1985a) Bajtin aparece como Baxtin.

${ }^{17}$ Cuando cita a Todorov, Guillén se refiere a la monografía que aquél dedicó a Bajtin en 1981.

${ }^{18}$ Guillén reprocha a Bajtin, por un lado, que se empeñara en denominar novela a la «totalidad de los géneros y subgéneros opuestos a la cultura grave o dominante» (en referencia al concepto de carnaval) convirtiéndola en una categoría «desaforadamente extensa» y «transhistórica» (1985a: 142), y, por el otro, que no tenga en cuenta que el diálogo no se realiza completamente en la novela (1985a: 239). Para la mención de Todorov véase la nota anterior.

${ }^{19}$ Tampoco me puedo ocupar como sería menester de los varios artículos en que Guillén estudia la novela picaresca como género y algunos de sus ejemplos significativos, como el Lazarillo, aunque haya mencionado uno que se ocupa de esta novela como punto de partida.

${ }^{20}$ Se trata, en realidad, de la combinación de textos varios escritos entre 2003 y 2006, no todos publicados (2007: 4061 517). A pesar de la restricción que me he impuesto, me concederé la libertad de aportar alguna cita de otros artículos. 
novelistas españoles, Luis Goytisolo, Antonio Muñoz Molina, Luis Mateo Díez y Javier Marías en un marco que quiere ser general sino exactamente comparatista ${ }^{21}$.

Sin embargo, mucho antes del artículo al que me refiero, Guillén ya sostiene que la novela moderna es un «complejo abierto de formas, polifonía, pluralidad de estilos, plasticidad devoradora de otros géneros» (1985a: 232). Sucede que en esta ocasión, al hilo de un comentario sobre Antagonía, de Luis Goytisolo, Guillén emplea un término tan discutible como el de plurinovela que le parece necesario justificar por una «variedad de cauces expresivos [que] va unida a una amplitud temática que es aún más importante que su origen formal. Los puntos de partida son desde luego la pluralidad de la persona y la prolijidad el mundo»(2003-2006b: 472 y 477). Destaca Guillén «la pluralidad que conduce al lector dinámicamente de una escritura literaria a otra, de un nivel de producción o de creación a otro, libre y móvilmente situados entre dos extremos: la anotación autobiográfica y la imaginación visionaria»; en esa obra la «querencia multigenérica [...] encuentra su oportunidad. Se destacan ante todo la ficción narrativa y la reflexión ensayística, unidas las dos como "escrituras del yo"» (2003-2006b: 476 y 475) 22.

En concreto, Guillén ve como características de esta tendencia de la novela contemporánea, en primer lugar, una «tendencia a la disposición multigenérica», es decir, la yuxtaposición o superposición en la misma obra de géneros distintos que se influyen entre sí o que participan de una «energía común» (2003-2006b: 464), y, en segundo lugar, «la tentativa de superación de la diferencia básica entre la expresión de lo inventado por el escritor y la reproducción de lo vivido por él», lo que supone, «en el fondo, [...] cuestionar el concepto mismo de ficción como fundamento el arte de escribir novelas» (2003-2006b: 467). Si de la primera característica destaca la confluencia entre el género ensayístico y la novela (2003-2206b: 466) ${ }^{23}$, pone la segunda en relación con la «introducción en la novela del yo real del autor [que] supone sobre todo, paradójicamente, una patente de corso para el ejercicio de la imaginación» (2003-2006b: 468) 24 .

Subraya Guillén que «en la novela se barajan tres cartas principales: la realidad personal del autor-narrador, la ficción de los personajes o de la trama, y la realidad de la circunstancia histórica», razón por la que insiste en que

\footnotetext{
${ }^{21}$ No dispongo de espacio suficiente para espigar referencias de indudable interés en otros artículos de la misma colección, como las observaciones sobre el contrato de lectura (para lo que convoca a Genette), que le llevan a considerar la estratificación de la obra y el papel que tienen en ella los objetos, pero también los vacíos del texto (Ingarden e Iser) (2007: 36-39). No menos interesantes son los comentarios sobre la epifanía en J. Joyce y R. Chacel (1998b [2007: 237-240], 1985a: 375). En Múltiples moradas se hallan interesantes referencias sobre el realismo, citando a D. Villanueva (1998a: 130-137), a propósito el paisaje; y sobre la ficcionalidad y la epistolaridad, recurriendo a J. Ma Pozuelo y P. Lejeune (1998a: 184-190).

${ }^{22}$ En Entre lo uno y lo diverso habla Guillén de «[1]o intergenérico de la novela moderna (o su pluralidad de lenguas y dialectos) [que] no significa por fuerza una visión crítica o extraoficial de la sociedad» (1985a: 176). El sintagma «escrituras del yo» es una referencia a Pozuelo (2005).

23 Dice Guillén en otro lugar que «[a]lgún crítico denomina estos textos "híbridos", lo que no suele resultar satisfactorio, ya que en no pocos casos los distintos modelos genéricos conservan su integridad y sin embargo hacen posible que el autor consiga el ensamblaje de una obra conjuntada» (2003: 421).

24 Sostiene Guillén, a este propósito, que es «una de las paradojas de la historia literaria el que aquella ilimitada ambición de describir una sociedad entera, o una época entera, o el tránsito de una a otra, tuviera por consecuencia, en un gigante como Balzac, o Tolstoi, o Galdós, la potenciación y expansión de las virtualidades de lo imaginario» (2003: 432)
} 
[...] las mejores novelas actuales (las novelas inteligentes) [combinan] la anécdota vivida con lo imaginado, la experiencia supuestamente real del autor con la ficción supuestamente inventada de la novela. Al parecer la intervención del autor «real» garantiza la veracidad y credibilidad de la ficción. ¿O es más bien que se extiende así el terreno de lo ficcional? (2003-2006a: 454).

La consecuencia es que el «imperio de la ficción [...] no tiene límites, la imaginación o la invención que la nutre lo abarca todo y borra las fronteras entre lo real y lo irreal; y lo imprescindible entonces pasa a ser la voluntad [...] de distinguirla del fingimiento y de la mentira» (2003-2006a: 455). Ello es origen de «una fuerte tensión [...] entre la entrega a la ficcionalidad y su cuestionamiento; o más concretamente, entre un egocentrismo inventado por parte del autor, y la prioridad de la imaginación de lo otro y lo ajeno» (2003-2006b: 468). Precisa todavía más esta deliberada confusión o fusión entre autor y narrador al afirmar que «[p]ersonaje céntrico, en suma, pero no héroe, [es] el autor de ciertos diarios y libros de ensayos. Personaje céntrico [es también] el yo ficcionalizado de ciertas novelas de primer orden. Ambos son los protagonistas de [...] "la vuelta al yo"», que Guillén considera un rasgo distintivo de parte de la literatura actual (2003-2006b: 471). Quizá por ello puede afirmar que el «escritor de hoy, de fines del siglo XX y principios del XXI, verdaderamente actual, en su uso de cualquier género literario, ya no reproduce el mundo sino lo va enriqueciendo y recreando desde la escritura. Es como si la literatura volviera a empezar» (2005: 442)

Guillén reconoce, por supuesto, que sólo ha desbrozado una pequeña parte del territorio de la novela española contemporánea ocupándose de unos pocos novelistas, aunque sean tan significativos como Luis Goytisolo, Antonio Muñoz Molina, Luis Mateo Díez y Javier Marías. Se ve obligado a conceder, en fin, que lo que ha llamado «plurinovela» es sólo un componente de ese conjunto o una tendencia, «pluralista o plurinovelesca». Pero insiste Guillén en que, si de una tendencia se trata, de ella

[...] cabe deducir que unos escritores de muy primer orden ya no estiman que la función representativa y significativa de la novela pueda proceder básicamente de la existencia ficcional de un ser humano individual, ni de varios, ni de su circunscripción a parcelas sociales o nacionales determinadas. Las individualidades sin duda existen y nos importan, como también las ciudades, regiones y otras comunidades humanas, pero su interés tiene que proceder de su pertenencia a los conjuntos que construyen un extenso, complejo mundo plural y sus valores virtuales.

Ante semejante reto qué duda cabe que se afirma y perdura, renaciente, la confianza en la palabra.

[...] Pero no sé si son éstas las únicas perplejidades que compartimos con estos grandes novelistas, las únicas ignorancias que los lectores experimentamos como ellos y con ellos, tan conscientes de cuanto se sabe, y no sé si el desconcierto ante el devenir de los seres y las sociedades no se nos muestra en estas obras más amplio y a la vez más íntimo que nunca, como si implicara la temporalidad desde lejos y desde muy ceca, como si se nos volviera problemática toda relación con el tiempo mismo, como si hubiéramos perdido el tiempo (2003-2006b: 514-515).

Después de leer esta última cita me permitiré subrayar lo bien que escribe Claudio Guillén, lo bien que se explica, en un movimiento que va de lo general a lo particular y de vuelta a lo general, que nunca pierde de vista la categoría cuando lee los textos con minuciosa atención y aguda sensibilidad, siempre flexible en la aplicación de los conceptos teóricos, sin renunciar jamás a ellos. Es innegable también su preocupación por el tiempo, que le lleva a prestar atención tanto a la dimensión histórica 
de la literatura como a la inscripción, modulación y modelación del tiempo en las novelas ${ }^{25}$. Me parece digno de todo elogio su capacidad para detectar y apreciar la pluralidad y la complejidad, sin olvidar nunca que la literatura de alguna manera refracta un estado del mundo, sin perder de vista que las novelas tienden hacia la unidad. En un plano más general, tampoco olvida que tan necesarias son la teoría y la crítica como la historia de la literatura, razón por la que se explica su vigilante atención a lo multigenérico de la novela contemporánea.

He empezado diciendo que Claudio Guillén disponía de una excelente información sobre teoría de la novela, que, patente en su obra anterior, supo administrar con criterio y decisión cuando escribió Entre lo uno y lo diverso. En esta obra, todavía de referencia obligada, dio cumplida noticia de las aportaciones de Stanzel y Cohn y supo valorar la importancia de Genette, aplicando siempre el criterio del rendimiento práctico de los conceptos que recogía. Volvió sobre alguno de esos autores y matizó y amplió algunos conceptos teóricos narrativos, prestando particular atención a novelistas españoles contemporáneos en los que halló terreno abonado para examinar problemas de interés teórico, temático, quizá también personal. Lo que he querido mostrar, en fin, es que Claudio Guillén unió desde el inicio de su carrera académica la reflexión teórica y la práctica crítica y las ejerció con indudable brillantez, combinando el rigor académico con una enorme curiosidad y calidez humana, hasta ayer mismo. Me permitiré terminar parafraseando unas palabras suyas que acabo de citar: leamos a Claudio Guillén como si no hubiéramos perdido el tiempo.

\section{Referencias bibliográficas}

ADAM, J.-M. (1992): Les textes: types et prototypes. París, Nathan, 2001.

BARTHES, R. (1970): S/Z. París, Seuil, 1970.

CoHn, D. (1978): Transparent minds: Narrative modes for presenting consciousness in fiction. Princeton: Princeton UP, 1978. [Trad. esp. parcial de E. Turpin: «Técnicas de representación de la conciencia», en E. Sullà, 2001, pp. 205-213].

ERLICH, V. (1969): El formalismo ruso. Trad. de J. Cabanes. Barcelona, Seix Barral, 1974.

FORSTER, E. M. (1927): Aspectos de la novela. Trad. de G. Lorenzo. Madrid: Debate, 1983.

FRYE, N. (1957): Anatomy of criticism. Princeton, Princeton UP, 1971.

GenetTe, G. (1972): «Discours du récit», en Figures III. París, Seuil, pp. 65-282 [Trad. esp.: «Discurso del relato», en Figuras III. Barcelona: Lumen, 1991].

GuILlÉN, C. (1957): «La disposición temporal del Lazarillo de Tormes», en El primer siglo de Oro. Estudios sobre géneros y modelos. Barcelona: Crítica, 1988, pp. 49-65.

\footnotetext{
${ }^{25}$ De haber podido, hubiera merecido la pena enmarcar en el contexto teórico que he trazado el comentario de Sefarad, de Antonio Muñoz Molina, una novela que interesó muchísimo a Claudio Guillén por su compleja combinación de realidad y ficción, la poderosa presencia de figuras de exiliados (como lo fue él mismo) y el tratamiento del tiempo con una peculiar interrelación entre tiempo histórico y tiempo narrativo que ya he destacado que interesó al maestro desde sus inicios (20032006b: 485-494).
} 
(1962): «Toward a definition of the picaresque», en C. GuILLÉN, 1971, pp. 71-106 [fechado en el texto: 1961].

- (1965-1968a): «On the uses of literary genre», en C. GuILlÉn, 1971, pp. 107-134.

(1965-1968b): «El descubrimiento del género picaresco», en C. GuILLÉN, 1988, pp. 197-211 [una versión anterior en 1971: 135-158].

- (1968): «On the concept and metaphor of perspective», en C. GUILLÉN, 1971, pp. 283-371.

- (1971): Literature as system: Essays toward the theory of literary history. Princeton, Princeton UP.

(1974): «De la forma a la estructura: fusiones y confusiones», en C. GuILLÉN, 1989a, pp. 139176.

(1985): Entre lo uno y lo diverso. Introducción a la literatura comparada. Barcelona, Tusquets, 2005.

_ (1985b): «Clarín: la morfología de la materia en La Regenta», en C. GuILLÉN, 2007, pp. 35-64. (1988): El primer siglo de Oro. Estudios sobre géneros y modelos. Barcelona, Crítica.

(1989a): Teorías de la historia literaria. Madrid, Espasa Calpe («Colección Austral»).

(1989b), «Pardo Bazán de la distancia a la ironía», en C. GuILlÉn, 2007, pp. 65-87.

_ (1998b): Múltiples moradas. Ensayo de literatura comparada. Barcelona, Tusquets.

(1998b): «Las epifanías de Rosa Chacel», en C. GuILlÉN, 2007, pp. 237-257.

- (2003-2006a): «Helder Macedo: literatura e inteligencia», en C. GUILLÉN, 2007, pp. 449-459.

— (2003-2006b): «Novelar de nuevo», en C. GUILLÉN, 2007, pp. 461-517.

- (2005): «Francisco Nieva: magisterio y ultracarnaval», en C. GUILLÉN, 2007, pp. 437-447.

(2006): «Galdós: la interliterariedad de los primeros Episodios», en C. GuILLÉN, 2007, pp. 13-

34.

(2007): De leyendas y lecciones. Siglos XIX, XX y XXI. Barcelona, Crítica.

INGARDEN, R. (1931): The literary work of art. Trad. de G. Grabowicz. Evanston, Norhtwestern UP,

1973 [Trad. esp.: La obra de arte literaria. Trad. de G. Nyenhuis. México, Universidad Iberoamericana/Taurus, 1998].

LEJEUnE, P. (1975): Le pacte autobiographique. París, Seuil.

LUBBOCK, P. (1921): The craft of fiction. Londres, Jonathan Cape, 1968.

PozUelo, J. Ma (1993): Poética de la ficción. Madrid, Síntesis.

(2005): «Teoría del ensayo», en J. M. ${ }^{a}$ Pozuelo, Desafíos de la teoría. Literatura y géneros.

Mérida (Venezuela) El otro el mismo, 2007, pp. 235-252.

SANMARTín, P., Otra historia del formalismo ruso. Madrid: Lengua de Trapo, 2008.

SEgRE, C. (1974): Las estructuras y el tiempo. Trad. de M. Arizmendi y M. Hernández Esteban. Barcelona, Planeta, 1976.

STANZEL, F. K. (1978): «Towards a “Grammar of fiction”», Novel 11/ 3, pp. 247-267. [Trad. esp.: «La mediación narrativa», en E. SULLÀ, 2001, pp. 226-237].

(1974): A theory of narrative. Cambridge, Cambridge UP, 1984. 
Sullà, E., ed. (1996): Teoría de la novela. Antología de textos del siglo XX. Barcelona, Crítica, 2001. Todorov, T. (1973): Grammaire du Décameron. La Haya, Mouton, 1969 [Trad. esp.: Gramática del Decamerón. Trad. de M. D. Echeverría. Madrid, J. Betancur]. (1981): Mikhaül Bakhtine. Le principe dialogique. París, Seuil.

ViLlanueVA, D. (2004): Teorías del realismo literario. Madrid, Biblioteca Nueva.

Villanueva, D., Monegal, A. y Bou, E., eds. (1999): Sin fronteras. Ensayos de Literatura Comparada en homenaje a Claudio Guillén. Madrid, Castalia. 